\section{Flip-flop end to last ice age}

\section{Richard G. Fairbanks}

THE most celebrated finding in ice-core research is the record of atmospheric $\mathrm{CO}_{2}$ concentration spanning the past 200,000 years. No doubt, future historians will debate the extent to which this record catalysed international interest in global warming forecasts. On page 527 of this issue, Richard Alley and coworkers report ice-core evidence of a different, but equally profound nature. From measurements of annual ice-layer thickness over the past 15,000 years, the authors find that Greenland's climate, emerging from the last ice age, twice shifted from glacial to interglacial conditions over an astonishingly quick 3-5 years.

This result apparently supports earlier claims that the Earth's climate system has several stable modes, between which it flips. At issue is whether these apparent climate shifts are driven by internal or external forces. Specifically, environmental scientists have posed the politically charged question: are the catastrophic climate changes measured in this and previous work at the crest of Greenland the result of climate boundary conditions unique to a glaciated North America, or could they recur tomorrow? Alley et al. contribute towards unravelling this problem in two ways. First, they establish the exact age and duration of these climate shifts. Second, they use ice accumulation rate as a simple index of climate change. Knowing the rate and timing of the shifts helps eliminate several postulated mechanisms.

The US Greenland Ice Sheet Project II (GISP2) will complete drilling through the Greenland ice cap sometime this summer. One objective of the GISP2 programme, and the parallel European effort GRIP (Greenland Icecore Project), is to date accurately the apparent shifts from glacial to interglacial conditions that have been observed in previous Greenland ice cores. Alley et al. examine the most recent shift to interglacial conditions (Younger Dryas/ Preboreal shift) and an earlier aborted shift (Older Dryas/Allerod). Armed with sophisticated sensors to detect subtle chemical and microparticle changes that are known to occur annually, the GISP2 team set out to measure annual layers in the Summit ice core one at a time from the surface to the last glacial period some 18,000 years ago. Compression of the ice and diffusion of the chemical species were expected to obliterate the annual signal beyond this period.
Much to the scientists' surprise, summer conditions left visible annual strata. Bleary-eyed after counting and recounting 15,000 layers, they discovered that the climate shifts occurred in less than a decade and that the shifts occurred approximately 1,000 years earlier than previously estimated from ice cores. Although such layer counting has a cre-

\section{IMAGE UNAVAILABLE FOR COPYRIGHT REASONS}

On the face of it, this seems like a happy ending that ties up the loose ends. However, that will require identifying a mechanism for a $7{ }^{\circ} \mathrm{C}$ climate warming that reached from North America, across Greenland, the North Atlantic and into central Europe. Analogies to the North Atlantic Oscillation, the much cited ocean-circulation link to climate, cannot apply over such distances. The prevailing theory that these climate shifts were triggered by the switching on of 'thermohaline' density-driven vertical circulation is very appealing; however, its advocates have a difficult, but not impossible, task in explaining $\infty$ mode changes that last only three years. Although areas of deep$\frac{c}{\frac{c}{x}}$ water convection are very localized, significant heat release from the ocean to the atmosphere, the control mechanism, requires large areas of ice-free water. How could sea ice come and go so quickly? In fact, an example of such rapid change did occur in the Southern Ocean in the 1970s. More difficult to explain is how the heat release from the thermohaline circulation (down wind of North America) contributed to the North American ice-sheet collapse. We can appeal to nonlinearities in the climate system and to the concept of climate thresholds, but glaciologists offer an alternative.

The GISP2 ice-core ages align the shifts to warmer climates precisely with the two periods of catastrophic ice-sheet collapse, as documented by the welldated changes in sea level recorded in Barbados corals. Glaciologists have argued that the two intervals of ice-sheet collapse were more probably driven by some extreme nonlinear response to slowly changing climate than by rapid climate change. Simple diffusion models of the Atlantic Ocean yield surface salinity drops in the North Atlantic of 3-10 per cent during the meltwater pulses associated with the collapse of the ice sheets. This creates a thin surface layer with relatively low thermal heat capacity which allows very rapid summer heating even at subpolar latitudes. With few exceptions, the proxy records of the two climate shifts can be explained by changes in seasonality ascribed to this mechanism.

The strong, rapid shifts described by Alley et al. occurred when the climate was sensitized by a long-term shift from glacial to the current interglacial conditions, but whether we should take comfort from that fact and the past 8,000 years of stability is debatable.

Richard G. Fairbanks is at the LamontDoherty Earth Observatory, Palisades, New York 10964, USA. 